\title{
IDENTIFICATION AND EVALUATION OF ANTICANCER COMPOUNDS FROM THREE NIGERIAN PLANTS USED IN TRADITIONAL MEDICINES
}

\author{
Okiemute Rosa Johnson-Ajinwo, Alan Richardson, Wen-Wu Li ${ }^{*}$
}

Institute for Science and Technology in Medicine, Keele University, Stoke-on-Trent ST4 7QB, United Kingdom

*Correspondence: w.li@keele.ac.uk; Tel: +44 (0)1782 674382

Ovarian cancer is the second leading cause of death among women in the gynaecological category of cancers. The current post surgery treatment which involves the use of platinumbased therapy with its attendant adverse drug-resistance often results in the return of the cancer. This study explored the role of phytochemicals as the major source of new drugs by the evaluation of the anti-ovarian cancer activities of three selected Nigerian medicinal plants (Acalypha wilkesiana, Margaritaria discoidea and Rutidea parviflora). Using a bioassayguided approach, an investigation of the cell growth inhibition of the extracts/fractions of these plants on four human ovarian cancer cell lines, A2780, OVCAR 4, OVCAR 8, and CISA2780 showed that these plant extracts had promising anti-ovarian cancer activities. The bioactive compounds of the plants were isolated by HPLC, identified by mass spectrometry/NMR spectroscopy and investigated for cytotoxicity. Gallic acid ( $\mathrm{IC}_{50}$ range of $6.2 \pm 0.3-26.9 \pm 4.1 \mu \mathrm{M})$ was the active compound in $A$. wilkesiana. The significantly bioactive compounds of $M$. discoidea were securinine $\left(\mathrm{IC}_{50}\right.$ range of $\left.2.7 \pm 0.7-8.7 \pm 0.1 \mu \mathrm{M}\right)$ [1], betulinic acid $\left(\mathrm{IC}_{50}\right.$ of $\left.16.0 \pm 1.9 \mu \mathrm{M}\right)$, and gallic acid. While palmatine $\left(\mathrm{IC}_{50}\right.$ range of $5.5 \pm 0.9-7.9 \pm 0.5 \mu \mathrm{M})$ was the major active compound in $R$. parviflora. Palmatine, and securinine showed induction of apoptosis via increased caspase 3/7 activity. Palmatine 
demonstrated PAPR cleavage by western blot analysis. These studies have provided scientific evidences for the potential treatment of ovarian cancer with these traditional medicinal plants and hit compounds for future optimization towards clinical trials.

1. Johnson-Ajinwo OR, Richardson A, Li WW. (2015) Cytotoxic effects of stem bark extracts and pure compounds from Margaritaria discoidea on human ovarian cancer cell lines. Phytomedicine 22: 1-4 